\title{
ASSOCIATION BETWEEN RISK OF OBSTRUCTIVE SLEEP APNEA AND COGNITIVE PERFORMANCE, FRAILTY, AND QUALITY OF LIFE AMONG OLDER ADULTS WITH ATRIAL FIBRILLATION
}

\author{
A Master's Thesis Presented
}

BY

JORDY MEHAWEJ, MD

\begin{abstract}
Submitted to the Faculty of the
University of Massachusetts Graduate School of Biomedical Sciences, Worcester in partial fulfillment of the requirements for the degree of
\end{abstract}

MASTER OF SCIENCE

March 18, 2021

BIOMEDICAL SCIENCES

HEALTH SERVICES RESEARCH 


\section{ASSOCIATION BETWEEN RISK OF OBSTRUCTIVE SLEEP APNEA AND COGNITIVE PERFORMANCE, FRAILTY, AND QUALITY OF LIFE AMONG \\ OLDER ADULTS WITH ATRIAL FIBRILLATION}

A Master's Thesis Presented

BY

JORDY MEHAWEJ, MD

The Master's Thesis Committee has given

approval as to style and content of the Thesis

Robert Goldberg, PhD, Chair of Committee

Shao-Hsien Liu, PhD, Member of Committee

David D. McManus, MD, ScM, Thesis advisor

The signature of the Dean of the Graduate School of Biomedical Sciences signifies that the student has met all master's degree graduation requirement of the school.

Dean of the Graduate School of Biomedical Sciences

Program

Master of Science in Clinical Investigation

March 18, 2021 


\section{ACKNOWLEDGEMENTS}

I would like to thank my mentor, Dr. David D. McManus, for his immense guidance, support, and genuine investment in my education. Dr. McManus has given me unbelievable trust, and invaluable advice throughout the past two years. I would also like to sincerely thank Dr. Robert J. Goldberg for his guidance, mentorship, and advice. Thank you to Mrs. Darleen Lessard, Dr. Jane Saczynski, Dr. Mayra Tisminetzky, and Dr. Weijia Wang for their contribution to this work.

I would also like to thank my colleagues in the Department of Population and Quantitative Health Sciences and the McManus Lab for their advice throughout the courses we took together and the papers we drafted together: Hawa Abu, MD; Eric Ding, MD/PhD candidate; Nisha Fahey, MD; Katarina Ferrucci, PhD candidate.

Lastly, I would like to thank the Center for Clinical and Translational Science (CCTS) at UMass Medical School for the funding I received for my postdoctoral fellowship and this MSCI program - award number 5T32HL120823. 


\section{ABSTRACT}

Background: Geriatric impairments and obstructive sleep apnea (OSA) are prevalent among patients with atrial fibrillation (AF) and adversely impact patient's long-term outcomes. Little is known, however, about the association between OSA and frailty, cognitive performance, and AF-related quality of life in older men and women with AF.

Objective: To examine the association of OSA with frailty, cognitive performance, and AFrelated quality of life among older adults with $\mathrm{AF}$.

Methods: Data from the Systemic Assessment of Geriatrics Elements-AF study were used which includes participants $\geq 65$ years with $\mathrm{AF}$ and a $\mathrm{CHA}_{2} \mathrm{DS}_{2}-\mathrm{VASc} \geq 2$. Multivariable adjusted logistic regression models were used to examine the association between OSA, as measured by the STOP-BANG questionnaire, and geriatric impairments including frailty, cognitive performance, and AF-related quality of life.

Results: A total of 970 participants with AF (mean age 75 years, 51\% male) were included in the analysis. Among the 680 participants without a medical history of OSA, 179 (26\%) participants had low risk of OSA, $360(53 \%)$ had an intermediate risk, and 141 participants (21\%) had a high risk for OSA. Compared to those with low risk of OSA, those at intermediate or high risk for OSA were significantly more likely to be frail $(\mathbf{a O R}=\mathbf{1 . 6 6}, 95 \% \mathrm{CI}$ : $1.08-2.56 ; \mathbf{a O R}=\mathbf{3 . 0 0}$, 95\% CI: 1.69-5.32, respectively) after adjusting for sociodemographic, clinical, and health behavioral variables. Risk of OSA was not associated with cognitive performance and AFrelated quality of life after adjusting for several potentially confounding factors.

Conclusions: Older adults with AF who are at intermediate or high risk for OSA have a greater likelihood of being frail. Our findings identify a group of patients at high risk who would benefit 
from early screening for OSA. Future longitudinal studies are needed to assess the effect of OSA treatment on frailty, physical functioning, and QoL among patients with AF.

Keywords: Atrial Fibrillation, Obstructive Sleep Apnea, Frailty, Cognitive Performance, AFrelated Quality of Life. 


\section{TABLE OF CONTENTS}

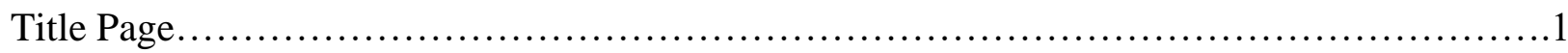

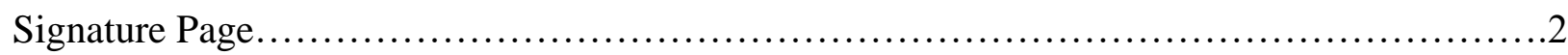

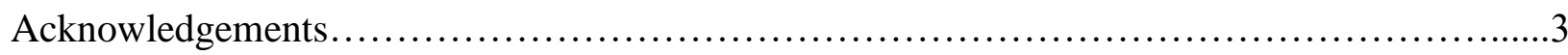

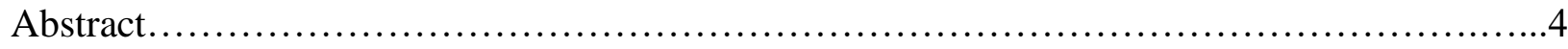

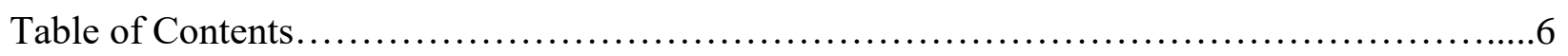

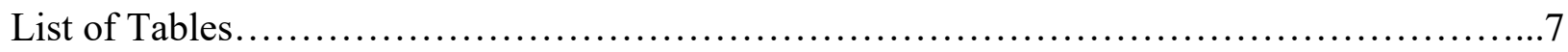

List of Third Party Copyrighted Material.................................................. 8

List of Symbols, Abbreviations, and Nomenclature............................................ 9

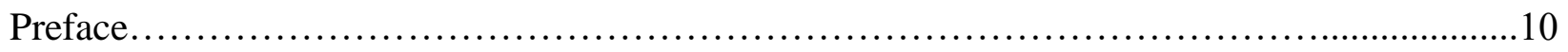

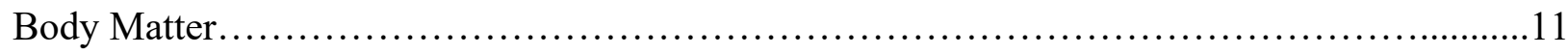

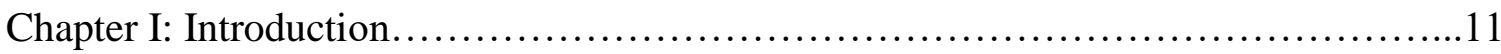

Chapter II: Methods.............................................................13

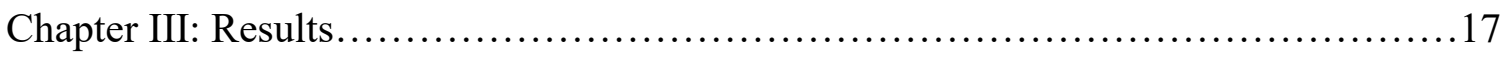

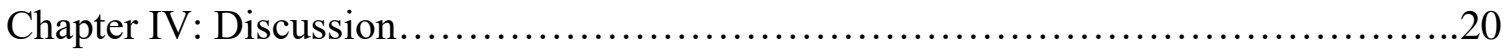

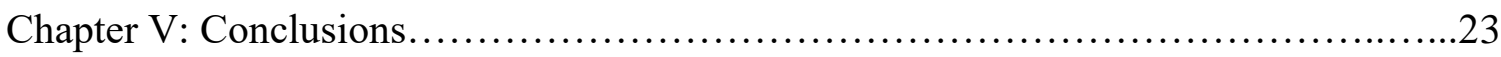

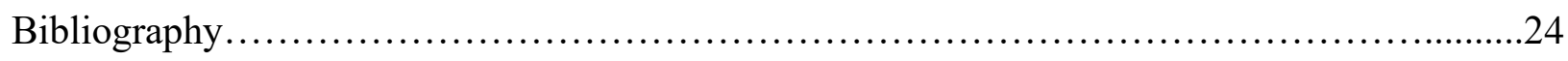

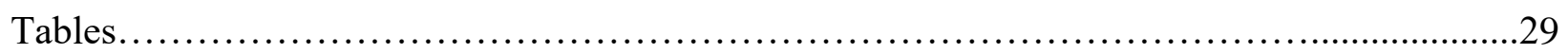




\section{LIST OF TABLES}

Table 1. Participants' Characteristics According to their Risk of Obstructive Sleep Apnea (OSA)

Table 2. Odds Ratios (95\% confidence intervals) for being "Frail" vs. "Not Frail" with Risk of OSA (STOP-BANG score) as the Independent Variable

Table 3. Odds Ratios (95\% confidence intervals) for Cognitive Impairment vs. Not Cognitively Impaired with Risk of OSA (STOP-BANG score) as the Independent Variable

Table 4. Odds Ratios (95\% confidence intervals) for reporting low AF related quality of Life "AFEQT $<80$ " (vs. high) with Risk of OSA (STOP-BANG score) as the Independent Variable

Supplementary Table 1. Participants' Characteristics According to their Medical History of OSA

Supplementary Table 2. Odds Ratios (95\% confidence intervals) for being "Frail" vs. "Not Frail" with Medical Hx of OSA as the Independent Variable

Supplementary Table 3. Odds Ratios (95\% confidence intervals) for Cognitive Impairment vs. Not Cognitively Impaired with Medical Hx of OSA as the Independent Variable

Supplementary Table 4. Odds Ratios (95\% confidence intervals) for reporting low AF related quality of Life "AFEQT $<80$ " (vs. high) with Medical Hx of OSA as the Independent Variable 


\section{LIST OF THIRD-PARTY COPYRIGHTED MATERIAL}

Appendix 1. STOP-BANG Questionnaire - Adopted from: Chung F, Abdullah HR, Liao P. STOP-Bang Questionnaire: A Practical Approach to Screen for Obstructive Sleep Apnea. Chest.

2016;149(3):631-8. doi: 10.1378/chest.15-0903. Epub 2016 Jan 12. PMID: 26378880. 
LIST OF SYMBOLS, ABBREVIATIONS, OR NOMENCLATURE

$\mathrm{AF}$ : atrial fibrillation

OSA: obstructive sleep apnea

COPD: chronic obstructive pulmonary disease

TIA: transient ischemic attack dual antiplatelet therapy

MOCA: montreal cognitive assessment

AFEQT: atrial fibrillation related quality of life

DM2: diabetes mellitus type 2

BMI: body mass index 


\section{PREFACE}

Atrial fibrillation $(\mathrm{AF})$ is the most common cardiac arrhythmia among adults, affecting approximately 34 million people worldwide. Geriatric impairments are common and adversely affect AF patient outcomes. Similarly, obstructive sleep apnea (OSA) is highly prevalent in patients with AF and has adverse health effects. However, there are extremely limited data on the association between geriatric elements and OSA among older adults with AF. To the best of our knowledge, only one published study has shown that patients with AF have lower cognitive performance. Guidelines recommend early screening for symptoms of OSA and treatment of OSA among patients with AF. Given this background, we examined the association between OSA and key geriatric elements including frailty, cognitive performance, and AF-related quality of life for purposes of identifying high risk groups who would benefit from early screening for OSA. 


\section{CHAPTER I. INTRODUCTION}

Atrial fibrillation (AF) is the most prevalent cardiac arrhythmia worldwide, affecting approximately 5 million individuals in the United States alone. [Ref-1] The prevalence of AF increases with advancing age and approximately doubles with every decade of life after the age of 40 years old. [Ref-2] Patients with AF often have multiple comorbidities including diabetes, hypertension, and obesity among others. [Ref-3] Geriatric impairments, including frailty, cognitive impairment, and poor health-related quality of life commonly occur in older patients with AF and adversely affect treatment outcomes and patient survival. [Ref-4,5] Obstructive sleep apnea (OSA) is also highly prevalent among patients with AF [Ref-6], affecting nearly one in every five of these individuals. This condition is caused by collapse in the pharyngeal airway causing breathing to stop involuntarily during sleep [Ref-7,8]; left untreated, OSA increases the risk of dying form cardiovascular disease and the risk of stroke independently of other stroke risk factors such as AF. [Ref-9-11] Individuals with both AF and OSA have higher risks of major bleeding and hospitalizations and worse functional status than patients with AF without OSA. [Ref-12]

Geriatric elements may be additional risk factors for OSA. However, whether OSA is associated with various impairments such as frailty and quality of life, among patients with AF has not been examined. Lower cognitive performance has been reported among AF patients with as compared to those without OSA. [Ref-13]. Among patients with AF, guidelines suggest clinicians use common signs and symptoms of AF to determine whether patients should be screened for OSA. [Ref-14] Inasmuch, identifying factors associated with OSA would help to identify patients with AF who are at high risk and who could benefit from screening, 
emphasizing the guideline recommendations of early screening for symptoms of OSA and its treatment among patients with AF. [Ref-15]

Using data from the Systematic Assessment of Geriatric Elements (SAGE)-AF study [Ref-16], we examined the association between OSA and frailty, cognitive performance, and AFrelated quality of life among older men and women with AF. We hypothesized that patients at high risk of OSA would more likely be frail, cognitively impaired, and have lower AF-related quality of life than patients defined as being at low risk for OSA using standardized measures of key study variables. 


\section{CHAPTER II. METHODS}

\section{Study Population}

The present study used data from the prospective multi-center cohort study, SAGE-AF. [Ref-16] Details of the study protocol and recruitment of older men and women with AF have been previously described. [Ref-16,17] In brief, between 2016 and 2018, participants were recruited from several clinics in Massachusetts and Georgia. Eligible participants included patients aged 65 years and older who were diagnosed with non-valvular AF and had a $\mathrm{CHA}_{2} \mathrm{DS}_{2-}$ VASc $\geq 2$ [REF-18]. Participants with documentation of an absolute contraindication to oral anticoagulation, those who were unable to provide informed consent [Ref-19], and those who did not speak English were deemed ineligible. The Institutional Review Boards at the University of Massachusetts Medical School, Mercer University, and Boston University approved this study. Prior to formal study enrollment, each eligible participant provided written informed consent.

Participants' baseline medical records were reviewed by trained research staff who abstracted data on study participants' demographic, clinical, and laboratory characteristics. The sociodemographic characteristics included age, sex, race, marital status, and level of education. Clinical factors included type of AF, time since AF diagnosis, body mass index (BMI), lifestyle practices and medical history (i.e., alcohol use, anemia, asthma/COPD, diabetes, heart failure, hypertension, major bleeding, myocardial infarction, peripheral vascular disease, obstructive sleep apnea, renal disease, and stroke/TIA), calculated stroke and bleeding risk scores, and relevant laboratory findings. Study participants also completed a structured in-person interview and a comprehensive geriatric assessment which assessed frailty, cognitive performance, and 
AF-related quality of life using standardized instruments. Participants self-reported whether or not they had a fall in the past 6 months and had any sensory deficits (i.e., visual and hearing).

\section{Risk for Obstructive Sleep Apnea}

The STOP-BANG questionnaire (Appendix 1), an 8-item questionnaire, [Ref 20] was used to assess the risk of OSA among SAGE-AF participants at the year 2 follow-up examination. The STOP-BANG questionnaire was not assessed at baseline. All items of the STOP-BANG questionnaire were self-reported, except for the neck circumference. This was measured by study research personnel using a standard protocol. [REF-20] For each of the 8 STOP-BANG questions, answering "Yes" equated to a score of 1 point on validated 8-point scale to categorize OSA risk into low, intermediate, or high: (1) a score of 0-2 indicates a low risk of OSA, (2) a score of 3-5 indicates an intermediate risk of OSA, and (3) a score of 6-8 indicates a high risk for OSA. [Ref-20]

Assessment of Frailty, Cognitive Performance, and AF- related Quality of Life

The Cardiovascular Health Survey (CHS) frailty scale [Ref-21], a five-component model of frailty that includes weight loss/shrinking, slow gait speed (15-foot times walk), exhaustion, poor physical activity measured by the Minnesota Leisure Time Activity questionnaire [Ref-22], and weakness (grip strength), was used to assess frailty in study participants at baseline. Each component received a single point with total score ranging from 0-5. A participant was considered to be robust if none of the criteria were met, pre-frail if 1 or 2 criteria were met, and frail if $\geq 3$ criteria were met. [Ref-21] 
The Montreal Cognitive Assessment Battery (MoCA), a 30-item screening tool, was used to assess cognitive performance among SAGE-AF participants at baseline. Scores range between 0 and 30 with lower scores indicating poorer cognitive performance. Participants with a score $\leq$ 23 were classified as being cognitively impaired. [REF-23,24]

The Atrial Fibrillation Effect on Quality of Life (AFEQT) questionnaire, a 20-item questionnaire, was used to assess participants' AF related quality of life at baseline. [REF-25] Participants self-reported the degree to which AF has affected their quality of life in the past 4 weeks. An overall AFEQT score, ranging from 0 to 100, was derived by adding the responses to 3 subscales: (1) daily activities, (2) symptoms, and (3) treatment concerns. Participants with an AFEQT score $\geq 80$ indicate a higher reported quality of life. [Ref-26]

\section{Statistical Analysis}

We compared the 3 levels of risk for OSA according to SAGE-AF participants' sociodemographic, clinical, geriatric, and psychosocial characteristics. The Chi-square test was used to examine between group differences in categorical variables. Unpaired t-tests and ANOVA were used to examine between group differences for continuous variables.

Separate multivariable adjusted logistic regression models were used to examine the association between the risk for OSA with each of the following: (1) frailty, (2) cognitive performance, and (3) AF-related quality of life. A model building approach was used to control for several potentially confounding variables in examining these associations. We adjusted for variables based on their level of statistical significance $(\mathrm{p}<0.05)$ with regards to their independent association with the risk of OSA. In model 1, sociodemographic variables including age, sex, race and marital status were included. We subsequently added clinical variables (i.e., 
symptoms of $\mathrm{AF}$, type of $\mathrm{AF}, \mathrm{AF}$ duration, and medical history) and health behaviors (i.e., smoking status) in the second regression model. A secondary analysis was performed to examine the association between patient's medical history of OSA and frailty, cognitive performance, and AF-related quality of life. All statistical analyses were performed using SAS c9.4 (SAS Institute Inc., Cary, NC, USA). 


\section{CHAPTER III. RESULTS}

A total of 970 SAGE-AF participants were included in the present study. The mean age of our study sample was 75 years old, approximately one- half were men, $87 \%$ were nonHispanic white, and 57\% were married; $60 \%$ had paroxysmal AF. Approximately $39 \%$ of participants were cognitively impaired, $64 \%$ were frail or prefrail, and the average AF-related quality of life was 81 , suggesting a relatively high AF-related quality of life among study participants.

A total of 290 (30\%) participants had a medical history of OSA. Among the 680 participants without a medical history of OSA, $179(26 \%)$ were classified as having a low risk of OSA, $360(53 \%)$ were at intermediate risk of OSA, and $141(21 \%)$ had a high risk for OSA. Risk of OSA and Frailty, Cognitive Performance, and AF-Related QoL

A significantly higher proportion of women (85\%) and non-Hispanic whites (91\%) were in the low OSA risk group while a higher proportion (43\%) of cognitively impaired participants were in the intermediate OSA risk group (Table 1). A significantly higher proportion of participants with a medical history of diabetes, hypertension, and PVD were in the high risk of OSA risk group (Table 1).

Participants with an intermediate or high, as compared to those with a low, risk of OSA were significantly more likely to be frail than not frail after adjusting for other sociodemographic and clinical variables (Table 2; adjusted OR $[\mathrm{aOR}]=1.66,95 \%$ CI: 1.08-2.56; $\mathrm{aOR}=3.00$, 95\% CI: 1.69-5.32, respectively). 
Participants with an intermediate risk of OSA, compared to those with a low risk of OSA, were more likely to be cognitively impaired than not impaired in the unadjusted model (Table 3; unadjusted $\mathrm{OR}=\mathbf{1 . 5 4}, 95 \% \mathrm{CI}$ : 1.06-2.23). This association, however, was no longer statistically significant after adjusting for a number of sociodemographic, clinical, and health behavioral variables in regression models 1 and 2.

Participants at high risk for OSA, compared to those with a low risk of OSA, were more likely to have a low AF-related quality of life after adjusting for several sociodemographic variables (Table 4; adjusted $O R=\mathbf{2 . 2 0 , 9 5 \%}$ CI: 1.29-3.76). This association remained but was no longer statistically significant after adjusting for a number of clinical and health behavioral variables in regression model \# 2.

Medical History of OSA and Frailty, Cognitive Performance, and AF-Related QoL

Participants with paroxysmal AF, a higher average BMI, a medical history of anemia, asthma, diabetes, heart failure, hypertension, and major bleeding were significantly more likely to have a medical history of OSA. Similarly, a higher proportion of frail participants (18\%) and those with a lower AF-related quality of life were significantly more likely to have a medical history of OSA (Supplemental Table 1).

Participants with a medical history of OSA, compared to those without, were more likely to be frail and have a low AF-related quality of life after adjusting for other sociodemographic and clinical variables (Supplemental Tables 2 and 4; adjusted OR = 1.59, 95\% CI: 1.122.24; adjusted OR $=1.80,95 \%$ CI: $1.27-2.55$, respectively).

Participants with a medical history of OSA, compared to those without, were less likely to be cognitively impaired than not impaired in the unadjusted model (Supplemental Table 3; unadjusted $\mathrm{OR}=\mathbf{0 . 7 9}, 95 \% \mathrm{CI}: \mathbf{0 . 5 9 - 1 . 0 5}$ ). The statistical significance of the association 
between a medical history of OSA and cognitive impairment were attenuated after multivariable adjustment for key covariates, including age and BMI. (terrific write-up of the results section as clear and succinct) 


\section{CHAPTER IV. DISCUSSION}

In this contemporary study of older adults with AF in whom the risk for OSA was systematically characterized, slightly more than one half of study participants were classified as being at intermediate risk for OSA. Study participants with AF with an intermediate or high risk for OSA had higher odds of being frail, but we failed to observe an association between risk of OSA and cognitive performance after multivariable adjustment.

Geriatric impairments, including frailty and impaired cognition, commonly occur in older patients with AF and have been shown to be associated with poor anticoagulation adherence and treatment related outcomes including increased risk of stroke and all-cause mortality [Ref-27,28] On the other hand, OSA is also highly prevalent among patients with AF and is associated with greater risks of major bleeding and hospitalizations, poorer treatment outcomes, and often contributes to the less than optimal maintenance and recurrence of AF. [Ref-29] To the best of our knowledge, no prior study has examined the association between OSA and various geriatric elements, including frailty and AF-related quality of life, among patients with AF, irrespective of the patient's age. Examining these associations will help in the identification of a group of highrisk patients who would benefit from screening for OSA.

Our observational study showed that participants at an intermediate or high risk for OSA were more likely to be frail, after adjusting for other potential confounders. In a cross-sectional study of 1,042 healthy adults, severe sleep disordered breathing was associated with a greater likelihood of components of the frailty measure utilized including slow walking speed and low grip strength [REF-30]. Health care providers need to be increasingly aware that OSA may be 
associated with frailty in older adults with AF, and, therefore, consider early screening for OSA in these patients which may provide an opportunity for early treatment of OSA.

In the present study, participants with an intermediate risk of OSA, compared to those with low risk of OSA, were more likely to be cognitively impaired. These associations remained but were no longer statistically significant after adjusting for other potentially confounding variables. In a study which included 122 participants with AF, participants with sleep apnea had lower cognitive performance and had greater problems in concentrating, when compared to those without OSA. [REF-13] In contrast, our study features a larger sample of patients diverse in geographic location, race, and comorbid conditions. Differences between our findings and previous studies could be related to the questionnaires used to determine OSA and cognitive performance and to differences in the sociodemographic and clinical characteristics of the respective study samples.

Our study showed that participants at high risk for OSA reported a lower AF-related quality of life. This association was no longer statistically significant, however, after adjusting for several confounding variables but the directionality of this association remained; our secondary analysis showed that those with a medical history of OSA were more likely to have a lower AF-related quality of life. Prior studies have shown lower health-related quality of life among patients with OSA [Ref-31] and poor sleep quality has also been shown to negatively impact quality of life among patients with hypertrophic obstructive cardiomyopathy. [Ref-32]

In the present large observational study, we sought to understand the links between OSA and key geriatric domains that impact AF outcomes and care. Our findings identify high risk groups that may benefit from current guideline recommendations of screening for OSA among older men and women with AF. We hypothesize that OSA might be associated with frailty 
among older patients with AF due to changes in physical function. This may be attributed to the symptoms of OSA including fatigue, excessive daytime sleepiness, and poor sleep quality. Healthcare providers should identify and screen group of patients at high risk as well as recommend early lifestyle and medical interventions aimed at treating OSA and its associated symptoms.

\section{Study Strengths and Limitations}

This large observational study has several strengths. First, we used data from a multicenter prospective cohort of older adults with AF with detailed sociodemographic, clinical, geriatric, and psychosocial characteristics. Second, study participants had multiple comorbidities and other potentially confounding factors which were accounted for in our analysis, enhancing the generalizability of our findings to older patient populations with AF. Third, we utilized standardized, validated instruments to assess the risk of OSA, AF-related quality of life, frailty, and cognitive performance, increasing the validity and reproducibility of our study findings. However, several limitations should be noted. Our study cohort consists mainly of Non-Hispanic White which limits the generalizability of our findings to ethnic minority groups. In addition, the present study examined the association between the risk of OSA collected at year 2 and the principal outcomes of interest collected at baseline. Literature showed no change in participants' STOP-BANG scores over time which addresses the limitation of temporality. A cross-sectional analysis will be done at year 2 once data on our principal outcomes at year 2 have been collected. Lastly, our study cohort was recruited from mostly academic medical centers which may limit the generalizability of our findings to community-based practices. 


\section{CHAPTER V. CONCLUSIONS}

Our study showed that, among older adults with AF, those determined to be at intermediate or high risk for OSA were more likely to be classified as frail. These findings highlight a group of older patients at high risk for OSA who may benefit from early screening. Future longitudinal studies are needed to examine the impact of OSA on geriatric elements, and whether OSA treatment increases quality of life and improves physical functioning in older adults with AF. 


\section{BIBLIOGRAPHY}

1. Colilla S, Crow A, Petkun W, Singer DE, Simon T, Liu X. Estimates of current and future incidence and prevalence of atrial fibrillation in the U.S. adult population. Am J Cardiol. 2013;112 (8):1142-1147.

2. Kannel WB, Benjamin EJ. Status of the epidemiology of atrial fibrillation. Med Clin North Am. 2008;92(1):17-ix. doi:10.1016/j.mcna.2007.09.002

3. January CT, Wann LS, Alpert JS, Calkins H, Cigarroa JE, Cleveland JC Jr, et al. AHA/ACC/HRS guideline for the management of patients with atrial fibrillation: executive summary: a report of the American College of Cardiology/American Heart Association Task Force on practice guidelines and the Heart Rhythm Society. Circulation. 2014; 130(23):2071-104. doi:10.1161/CIR.0000000000000040

4. Gugganig R, Aeschbacher S, Leong DP, et al. Frailty to predict unplanned hospitalization, stroke, bleeding, and death in atrial fibrillation. European Heart JournalQuality of Care and Clinical Outcomes. 2021; 7(1): 42-51.

5. Ball J, Løchen M-L, Carrington MJ, et al. Mild cognitive impairment impacts health outcomes of patients with atrial fibrillation undergoing a disease management intervention. Open Heart. 2018;5:e000755. doi:10.1136/ openhrt-2017-000755

6. Gami AS, Pressman G, Caples SM, et al. Association of atrial fibrillation and obstructive sleep apnea. Circulation. 2004;110(4):364-367.

doi:10.1161/01.CIR.0000136587.68725.8E

7. Peppard PE, Young T, Barnet JH, Palta M, Hagen EW, Hla KM. Increased prevalence of sleep-disordered breathing in adults. Am J Epidemiol. 2013; 177(9):1006-14. doi:10.1093/aje/kws342 
8. Young T, Skatrud J, Peppard PE. Risk factors for obstructive sleep apnea in adults. JAMA. 2004; 291(16):2013-6. doi:10.1001/jama.291.16.2013

9. Molnar MZ, Mucsi I, Novak M, Szabo Z, Freire AX, Huch KM, et al. Association of incident obstructive sleep apnoea with outcomes in a large cohort of US veterans. Thorax. 2015; 70(9):888-95. doi:10.1136/thoraxjnl-2015-206970

10. Young T, Finn L, Peppard PE, Szklo-Coxe M, Austin D, Nieto FJ, et al. Sleep disordered breathing and mortality: eighteen-year follow-up of the Wisconsin sleep cohort. Sleep. 2008; 31(8):1071-8.

11. Redline S, Yenokyan G, Gottlieb DJ, Shahar E, O’Connor GT, Resnick HE, et al. Obstructive sleep apnea-hypopnea and incident stroke: the sleep heart health study. Am J Respir Crit Care Med (2010) 182(2):269-77. doi:10.1164/ rccm.200911-1746OC

12. Holmqvist F, Guan N, Zhu Z, et al. Impact of obstructive sleep apnea and continuous positive airway pressure therapy on outcomes in patients with atrial fibrillation-Results from the Outcomes Registry for Better Informed Treatment of Atrial Fibrillation (ORBIT-AF). Am Heart J. 2015;169(5):647-654.e2. doi:10.1016/j.ahj.2014.12.024

13. Diaconu N, Grosu A, Lupusor A, Dragan I. Correlation between obstructive sleep apnea syndrome and cognitive impairment in atrial fibrillation patients. European Heart Journal. 2017; 38 (1): 4588.

14. Hindricks G, Potpara T, Dagres N, et al. 2020 ESC Guidelines for the diagnosis and management of atrial fibrillation developed in collaboration with the European Association for Cardio-Thoracic Surgery (EACTS): The Task Force for the diagnosis and management of atrial fibrillation of the European Society of Cardiology (ESC) 
Developed with the special contribution of the European Heart Rhythm Association (EHRA) of the ESC, European Heart Journal. 2020; 42 (5): 373-498.

15. Kirchhof P, Benussi S, Kotecha D, et al. 2016 ESC Guidelines for the management of atrial fibrillation developed in collaboration with EACTS. EP Europace. 2016; 18(11): 1609-1678. https://doi.org/10.1093/europace/euw295

16. Saczynski JS, Sanghai SR, Kiefe CI, et al. Geriatric Elements and Oral Anticoagulant Prescribing in Older Atrial Fibrillation Patients: SAGE-AF. J Am Geriatr Soc. 2020;68(1):147-154. doi:10.1111/jgs.16178

17. Wang W, Saczynski J, Lessard D, et al. Physical, cognitive, and psychosocial conditions in relation to anticoagulation satisfaction among elderly adults with atrial fibrillation: The SAGE-AF study. J Cardiovasc Electrophysiol. 2019;30(11):2508-2515. doi:10.1111/jce.14176

18. Odum LE, Cochran KA, Aistrope DS, Snella KA. The CHADS 2 versus the new CHA2DS2VASc scoring systems for guiding antithrombotic treatment of patients with atrial fibrillation: review of the literature and recommendations for use. Pharmacotherapy. 2012;32(3):285-296. doi:10.1002/j.1875-9114.2012.01023.x

19. Schmitt EM, Marcantonio ER. Alsop DC, et al. Novel risk markers and long-term outcomes of delirium: the successful aging after elective surgery (SAGES) study design and methods. J Am Med Dir Assoc.2012;13(9): 818.e1-818.e10.

20. Chung F, Abdullah HR, Liao P. STOP-Bang Questionnaire: A Practical Approach to Screen for Obstructive Sleep Apnea. Chest. 2016;149(3):631-8. doi: 10.1378/chest.150903. Epub 2016 Jan 12. PMID: 26378880. 
21. Fried LP, Tangen CM, Walston J, et al. Frailty in older adults: Evidence for a phenotype. Journals Gerontol - Ser A Biol Sci Med Sci. 2001;56(3). doi:10.1093/gerona/56.3.m146

22. Elosua R, Garcia M, Aguilar A, Molina L, Covas MI, Marrugat J. Validation of the Minnesota Leisure Time Physical Activity Questionnaire In Spanish Women. Investigators of the MARATDON Group. Med Sci Sports Exerc. 2000;32(8):1431-1437. doi:10.1097/00005768-200008000-00011

23. Nasreddine ZS, Phillips NA, Bédirian V, et al. The Montreal Cognitive Assessment, MoCA: A brief screening tool for mild cognitive impairment. J Am Geriatr Soc. 2005;53(4):695-699. doi:10.1111/j.1532-5415.2005.53221.x

24. Saczynski JS, Inouye SK, Guess J, et al. The Montreal cognitive assessment: creating a crosswalk with the Mini-Mental State Examination. J Am Geriatr Soc.2015;63(11):23702374.

25. Spertus J, Dorian P, Bubien R, et al. Development and validation of the Atrial Fibrillation Effect on QualiTy-of-life (AFEQT) questionnaire in patients with Atrial Fibrillation. Circ Arrhythmia Electrophysiol. 2011;4(1):15-25. doi:10.1161/CIRCEP.110.958033

26. Katsumata Y, Kohsaka S, Ikemura N, et al. Symptom underrecognition of atrial fibrillation patients in consideration for cather ablation: a report from Kics-AF Registry. JACC: Clinical Electrophysiology. 2020; In press. doi: 10.1016/j.jacep.2020.10.016

27. Madhavan M, Holmes DN, Piccine JP, et al. Association of frailty and cognitive impairment with benefits of oral anticoagulation in patients with atrial fibrillation. Am Heart J. 2019;211:77-89. 
28. Induruwa I, Evans NR, Aziz A, Reddy S, Khadjooi K, Romero-Ortuno R. Clinical frailty is independently associated with non-prescription of anticoagulants in older patients with atrial fibrillation. Geriatr Gerontol Int. 2017;17(11)2178-2183.

29. Holmqvist F, Guan N, Zhu Z, Kowey P, et al. Obstructive sleep apnea and atrial fibrillation: Findings from ORBIT-AF. J Am Coll Cardiol. 2014; 63.

30. Endeshaw YW, Unruh ML, Kutner M, Newman AB, Bliwise DL. Sleep-disordered breathing and frailty in the Cardiovascular Health Study Cohort. Am J Epidemiol. 2009;170(2):193-202. doi:10.1093/aje/kwp108

31. Dutt N, Chaudhry K, Chauhan N, et al. Health Related Quality of Life in Adult Obstructive Sleep Apnea. J of Sleep Disord Ther. 2016; 5(2). DOI: 10.4172/21670277.1000234

32. Pedrosa RP, Lima SG, Drager LF, et al. Sleep quality and quality of life in patients with hypertrophic cardiomyopathy. Cardiology. 2010;117(3):200-206.

doi:10.1159/000321718 


\section{TABLES AND FIGURES}

\section{Appendix 1. STOP-BANG Questionnaire}

\begin{tabular}{|l|l|l|}
\hline STOP-BANG Questionnaire & Yes & No \\
\hline STOP & & \\
\hline $\begin{array}{l}\text { Do you SNORE loudly (louder than talking or loud enough to be } \\
\text { heard through closed doors?) }\end{array}$ & & \\
\hline Do you often feel TIRED, fatigued, or sleepy during daytime? & & \\
\hline Has anyone OBSERVED you stop breathing during your sleep? & & \\
\hline Do you have or are you being treated for high blood PRESSURE? & & \\
\hline BANG & & \\
\hline BMI more than $35 \mathrm{~kg} / \mathrm{m} 2 ?$ & & \\
\hline AGE over than 50 years old? & & \\
\hline NECK circumference $>16$ inches $(40 \mathrm{~cm}) ?$ & & \\
\hline GENDER: Male? & & \\
\hline
\end{tabular}


Table 1. Study Participants' Characteristics According to their Risk of Obstructive Sleep Apnea

\begin{tabular}{|c|c|c|c|c|}
\hline Characteristics & Low Risk (n=179) & $\begin{array}{c}\text { Intermediate Risk } \\
(\mathrm{n}=\mathbf{3 6 0})\end{array}$ & High Risk (n=141) & P-value \\
\hline $\begin{array}{l}\text { Socio-demographics } \\
\text { Age, years, (M, SD) } \\
\text { Women }(\%) \\
\text { Non-Hispanic White }(\%) \\
\text { Married (\%) } \\
\text { College graduate or more }(\%)\end{array}$ & $\begin{array}{c}76(7.3) \\
152(84.9) \\
163(91.1) \\
87(49.2) \\
86(48.9)\end{array}$ & $\begin{array}{c}77(7.1) \\
174(48.3) \\
303(84.2) \\
199(55.9) \\
146(41.1)\end{array}$ & $\begin{array}{c}75(5.9) \\
25(17.7) \\
127(90.1) \\
102(72.3) \\
76(53.9)\end{array}$ & $\begin{array}{c}0.07 \\
<\mathbf{0 . 0 0 1} \\
\mathbf{0 . 0 4} \\
<\mathbf{0 . 0 0 1} \\
\mathbf{0 . 0 2} \\
\end{array}$ \\
\hline $\begin{array}{l}\text { Clinical } \\
\text { Mean Body Mass Index (BMI), kg/m2 } \\
\text { Type of AF (\%) } \\
\text { Paroxysmal } \\
\text { Persistent } \\
\text { Permanent } \\
\text { Left Ventricular Ejection Fraction, (SD) } \\
\text { EKG } \\
\text { Atrial Fibrillation (\%) } \\
\text { Normal Sinus (\%) } \\
\text { Heart Rate (M, SD) } \\
\text { Time since AF Diagnosis, mean, years (SD) } \\
\text { On Anticoagulation } \\
\text { Medical History (\%) } \\
\text { Alcohol Use } \\
\text { Anemia } \\
\text { Asthma/COPD } \\
\text { Diabetes } \\
\text { Hypertension } \\
\text { Major Bleeding } \\
\text { Myocardial Infarction } \\
\text { Peripheral vascular disease } \\
\text { Renal Disease } \\
\text { Stroke/TIA } \\
\text { Hemoglobin, (M, SD) } \\
\text { Charlson Comorbidity index, (M, SD) } \\
\text { Risk Scores (M, SD) } \\
\text { CHA }{ }_{2} \text { DS } 2 \text {-VASc } \\
\text { HAS-BLED }\end{array}$ & $\begin{array}{c}26(4.3) \\
113(63.1) \\
37(20.7) \\
11(6.2) \\
55(11.3) \\
\\
45(27.4) \\
66(40.2) \\
71(13.5) \\
5(4.3) \\
158(88.3) \\
\\
50(27.9) \\
52(29.1) \\
29(16.2) \\
24(13.4) \\
149(83.2) \\
24(13.4) \\
23(12.9) \\
15(8.4) \\
32(17.9) \\
16(8.9) \\
13(2) \\
5(1.7) \\
4(1.5) \\
3(1.0)\end{array}$ & $\begin{array}{c}29(5.3) \\
\\
203(56.4) \\
92(25.6) \\
21(6.9) \\
56(11.4) \\
\\
104(31.7) \\
118(36.0) \\
70(12.2) \\
5(4.2) \\
302(83.9) \\
\\
108(30.0) \\
96(26.7) \\
71(19.7) \\
84(23.3) \\
322(89.4) \\
59(16.4) \\
75(20.8) \\
51(14.2) \\
92(25.6) \\
35(9.7) \\
13(2) \\
6(1.9) \\
4(1.6) \\
3(1.1)\end{array}$ & $\begin{array}{c}32(6.4) \\
\\
74(52.5) \\
47(33.4) \\
8(5.7) \\
54(11.4) \\
\\
40(30.5) \\
44(33.6) \\
72(15.5) \\
5(4.5) \\
127(90.1) \\
\\
53(37.6) \\
33(23.4) \\
35(24.8) \\
39(27.7) \\
133(94.3) \\
27(19.2) \\
29(20.6) \\
24(17.0) \\
47(33.3) \\
13(9.2) \\
14(2) \\
6(2.6) \\
4(1.6) \\
3(1.1)\end{array}$ & $\begin{array}{c}0.92 \\
\\
0.22 \\
0.58 \\
0.13 \\
\\
0.15 \\
0.53 \\
0.16 \\
<\mathbf{0 . 0 1} \\
<\mathbf{0 . 0 1} \\
0.38 \\
0.06 \\
0.06 \\
<\mathbf{0 . 0 1} \\
0.95 \\
<\mathbf{0 . 0 1} \\
\mathbf{0 . 0 4} \\
\\
0.08 \\
<\mathbf{0 . 0 1}\end{array}$ \\
\hline $\begin{array}{l}\text { Psychosocial, Geriatric and Patient } \\
\text { Reported Elements } \\
\text { Frailty }(\%) \\
\quad \text { Not frail } \\
\text { Pre-frail } \\
\text { Frail } \\
\text { Social Isolation (\%) } \\
\text { Fall in Past } 6 \text { months (\%) } \\
\text { Cognitive Impairment (MOCA } \leq 23) \\
\text { AFEQT Score (M, SD) } \\
\end{array}$ & $\begin{array}{l}83(46.4) \\
76(42.5) \\
20(11.2) \\
19(10.6) \\
32(17.9) \\
63(35.2) \\
84(15.6) \\
\end{array}$ & $\begin{array}{c}137(38.1) \\
192(53.3) \\
31(8.6) \\
45(12.5) \\
80(22.2) \\
164(45.6) \\
83(15.7) \\
\end{array}$ & $\begin{array}{c}48(34.0) \\
81(57.5) \\
12(8.5) \\
18(12.8) \\
28(19.9) \\
46(32.6) \\
81(16.7) \\
\end{array}$ & $\begin{array}{c}0.78 \\
0.49 \\
<\mathbf{0 . 0 1} \\
0.15 \\
\end{array}$ \\
\hline Current smoker (\%) & $6(3.4)$ & $12(3.3)$ & $4(2.8)$ & $<0.001$ \\
\hline
\end{tabular}


Abbreviations: AF: Atrial Fibrillation; COPD: Chronic Obstructive Pulmonary Disease; TIA: Transient Ischemic Attack; $\mathrm{CHA}_{2} \mathrm{DS}_{2^{-}}$ VASc: stroke risk score; HAS-BLED: bleeding risk score; MOCA: Montreal Cognitive Assessment; AFEQT: AF-related quality of life

Table 2. Odds Ratios (95\% confidence intervals) for being "Frail” vs. "Not Frail” with Risk of Obstructive Sleep Apnea (STOP-BANG score)

\begin{tabular}{|l|c|c|c|}
\hline Risk of OSA & $\begin{array}{c}\text { Unadjusted } \\
\text { OR }(\mathbf{9 5 \%} \text { CI })\end{array}$ & $\begin{array}{c}\text { Model 1 } \\
\text { OR }(\mathbf{9 5 \%} \text { CI })\end{array}$ & $\begin{array}{c}\text { Model 2 } \\
\text { OR }(\mathbf{9 5 \%} \text { CI })\end{array}$ \\
\hline Low & Ref & Ref & Ref \\
\hline Intermediate & $1.41(0.98,2.02)$ & $\mathbf{1 . 8 3}(\mathbf{1 . 2 0 - 2 . 7 9})$ & $\mathbf{1 . 6 6}(\mathbf{1 . 0 8}-\mathbf{2 . 5 6})$ \\
\hline High & $\mathbf{1 . 6 8 ( 1 . 0 6 , 2 . 6 4 )}$ & $\mathbf{3 . 5 8}(\mathbf{2 . 0 5 - 6 . 2 6})$ & $\mathbf{3 . 0 0}(\mathbf{1 . 6 9 - 5 . 3 2})$ \\
\hline $\begin{array}{l}\text { Model 1: Adjusted for sociodemographic variables: age, sex, race, and marital } \\
\text { status. }\end{array}$ \\
$\begin{array}{l}\text { Model 2: Adjusted for variables in model 1, clinical variables (symptoms of AF, } \\
\text { type of AF, AF duration, medical history of DM2, renal disease, and smoking } \\
\text { status }\end{array}$ \\
\hline
\end{tabular}

Table 3. Odds Ratios (95\% confidence intervals) for Cognitive Impairment vs. Not Cognitively Impaired with Risk of Obstructive Sleep Apnea (STOP-BANG score)

\begin{tabular}{|l|c|c|c|}
\hline $\begin{array}{l}\text { Risk of } \\
\text { OSA }\end{array}$ & $\begin{array}{c}\text { Unadjusted } \\
\text { OR }(\mathbf{9 5 \%} \mathbf{C I})\end{array}$ & $\begin{array}{c}\text { Model 1 } \\
\text { OR } \mathbf{( 9 5 \%} \text { CI) }\end{array}$ & $\begin{array}{c}\text { Model 2 } \\
\text { OR }(\mathbf{9 5 \%} \text { CI) }\end{array}$ \\
\hline Low & Ref & Ref & Ref \\
\hline Intermediate & $\mathbf{1 . 5 4}(\mathbf{1 . 0 6}, \mathbf{2 . 2 3})$ & $1.21(0.78-1.87)$ & $1.16(0.75-1.81)$ \\
\hline High & $0.89(0.56,1.42)$ & $0.80(0.45-1.41)$ & $0.71(0.39-1.28)$ \\
\hline $\begin{array}{l}\text { Model 1: Adjusted for sociodemographic variables: age, sex, race, and marital } \\
\text { status. }\end{array}$ \\
$\begin{array}{l}\text { Model 2: Adjusted for variables in model 1, clinical variables (symptoms of AF; } \\
\text { type of AF; AF duration; medical history of DM2, Renal disease) and smoking } \\
\text { status }\end{array}$ \\
\hline
\end{tabular}


Table 4. Odds Ratios (95\% confidence intervals) for reporting low AF-related quality of Life “AFEQT < 80" (vs. high) with Risk of OSA (STOP-BANG score)

\begin{tabular}{|c|c|c|c|}
\hline Risk of OSA & $\begin{array}{c}\text { Unadjusted } \\
\text { OR }(95 \% \text { CI })\end{array}$ & $\begin{array}{c}\text { Model 1 } \\
\text { OR }(95 \% \text { CI })\end{array}$ & $\begin{array}{c}\text { Model } 2 \\
\text { OR }(95 \% \text { CI })\end{array}$ \\
\hline Low & Ref & Ref & Ref \\
\hline Intermediate & $1.17(0.80,1.71)$ & $1.48(0.98-2.24)$ & $1.41(0.90-2.20)$ \\
\hline High & $1.36(0.86,2.17)$ & $2.20(1.29-3.76)$ & $1.83(1.01-3.30)$ \\
\hline \multicolumn{4}{|c|}{$\begin{array}{l}\text { Model 1: Adjusted for sociodemographic variables: age, sex, race, and marital } \\
\text { status. } \\
\text { Model 2: Adjusted for variables in model 1, clinical variables (symptoms of AF } \\
\text { type of AF; AF duration; medical history of DM2, Renal disease) and smoking } \\
\text { status }\end{array}$} \\
\hline
\end{tabular}


Secondary Analysis:

Table 1. Participants' Characteristics According to Medical History of Obstructive Sleep Apnea

\begin{tabular}{|c|c|c|c|}
\hline \multirow[t]{2}{*}{ Characteristics } & \multicolumn{2}{|c|}{ Medical History } & \multirow[b]{2}{*}{ P-valus } \\
\hline & Yes $(n=290)$ & No $(n=680)$ & \\
\hline \multicolumn{4}{|l|}{ Socio-demographics } \\
\hline Age, years, (mean, SD) & $73(5.6)$ & $76(6.9)$ & $<0.001$ \\
\hline Women $(\%)$ & $123(42.4)$ & $351(51.6)$ & $<0.01$ \\
\hline Non-Hispanic White (\%) & 249 (85.9) & $593(87.2)$ & 0.53 \\
\hline Married (\%) & $170(58.8)$ & $388(57.6)$ & 0.72 \\
\hline College graduate or more $(\%)$ & $125(43.4)$ & $308(45.8)$ & 0.49 \\
\hline \multicolumn{4}{|l|}{ Clinical } \\
\hline Mean Body Mass Index (BMI), kg/m2 & $34(6.7)$ & $29(5.5)$ & $<0.001$ \\
\hline \multicolumn{4}{|l|}{ Type of $\mathrm{AF}(\%)$} \\
\hline Paroxysmal & $194(66.9)$ & $390(57.4)$ & $\mathbf{0 . 0 3}$ \\
\hline Persistent & $62(21.4)$ & $176(25.9)$ & \\
\hline Permanent & $9(3.1)$ & $40(5.9)$ & \\
\hline Left Ventricular Ejection Fraction, (SD) & $56(11.7)$ & $56(11.2)$ & 0.68 \\
\hline \multicolumn{4}{|l|}{ EKG } \\
\hline Atrial Fibrillation (\%) & $78(29.1)$ & $189(30.3)$ & 0.51 \\
\hline Normal Sinus (\%) & $110(41.0)$ & $228(36.6)$ & \\
\hline Heart Rate $(\mathrm{M}, \mathrm{SD})$ & $70(13.3)$ & $71(12.2)$ & 0.22 \\
\hline Time since AF Diagnosis, mean, years (SD) & $6(4.6)$ & $5(4.2)$ & $<0.001$ \\
\hline On Anticoagulation & $251(86.6)$ & $587(86.6)$ & 0.92 \\
\hline \multicolumn{4}{|l|}{ Medical History $(\%)$} \\
\hline Alcohol Use & $102(35.2)$ & $211(31.0)$ & 0.21 \\
\hline Anemia & $112(38.6)$ & $181(26.6)$ & $<0.001$ \\
\hline Asthma/COPD & $108(37.2)$ & $135(19.9)$ & $<0.001$ \\
\hline Diabetes & $109(37.6)$ & $147(21.6)$ & $<0.001$ \\
\hline Heart Failure & $122(42.1)$ & $213(31.3)$ & $<0.01$ \\
\hline Hypertension & $270(93.1)$ & $604(88.8)$ & 0.04 \\
\hline Major Bleeding & $64(22.1)$ & $110(16.2)$ & 0.03 \\
\hline Myocardial Infarction & $53(18.7)$ & $127(18.3)$ & 0.88 \\
\hline Peripheral vascular disease & $45(15.5)$ & $90(13.2)$ & 0.35 \\
\hline Renal Disease & $81(27.9)$ & $171(25.2)$ & 0.37 \\
\hline Stroke/TIA & $30(10.3)$ & $64(9.4)$ & 0.65 \\
\hline Hemoglobin, (mean, SD) & $13(1.9)$ & $13(1.8)$ & 0.45 \\
\hline Charlson Comorbidity index, (mean, SD) & $6(2.4)$ & $6(2.4)$ & 0.48 \\
\hline \multicolumn{4}{|l|}{ Risk Scores (mean, SD) } \\
\hline $\mathrm{CHA}_{2} \mathrm{DS}_{2}-\mathrm{VASc}$ & $4(1.6)$ & $4(1.6)$ & 0.55 \\
\hline HAS-BLED & $3(1.0)$ & $3(1.1)$ & 0.02 \\
\hline \multirow{3}{*}{\multicolumn{4}{|c|}{$\begin{array}{l}\text { Psychosocial, Geriatric and Patient } \\
\text { Reported Elements } \\
\text { Frailty }(\%)\end{array}$}} \\
\hline & & & \\
\hline & & & \\
\hline Not frail & $85(29.3)$ & $268(39.4)$ & $<0.001$ \\
\hline Pre-frail & $154(53.1)$ & $349(51.3)$ & \\
\hline Frail & $51(17.6)$ & $63(9.3)$ & \\
\hline Social Isolation (\%) & $39(13.5)$ & $82(12.1)$ & 0.55 \\
\hline Fall in Past 6 months (\%) & $71(24.5)$ & $140(20.6)$ & 0.18 \\
\hline Cognitive Impairment (MOCA $\leq 23$ ) & $100(34.5)$ & $273(40.2)$ & 0.10 \\
\hline AFEQT Score (M, SD) & $76(20.1)$ & $83(16.0)$ & $<0.001$ \\
\hline Current smoker (\%) & $3(1.0)$ & $22(3.2)$ & $\mathbf{0 . 0 2}$ \\
\hline
\end{tabular}


Abbreviations: AF: Atrial Fibrillation; COPD: Chronic Obstructive Pulmonary Disease; TIA: Transient Ischemic Attack; $\mathrm{CHA}_{2} \mathrm{DS}_{2}$-VASc: stroke risk score; HAS-BLED: bleeding risk score; MOCA: Montreal Cognitive

Assessment; AFEQT: AF-related quality of life

Table 2. Odds Ratios (95\% confidence intervals) for being "Frail" vs. "Not Frail" with Medical

History of OSA

\begin{tabular}{|c|c|c|c|}
\hline $\begin{array}{l}\text { Medical } \\
\text { History of OSA }\end{array}$ & $\begin{array}{c}\text { Unadjusted } \\
\text { OR }(95 \% \text { CI })\end{array}$ & $\begin{array}{c}\text { Model 1 } \\
\text { OR }(95 \% \text { CI })\end{array}$ & $\begin{array}{c}\text { Model } 2 \\
\text { OR }(95 \% \text { CI })\end{array}$ \\
\hline No & Ref & Ref & Ref \\
\hline Yes & $1.57(1.17-2.11)$ & $2.08(1.52-2.86)$ & $1.59(1.12-2.24)$ \\
\hline $\begin{array}{l}\text { Model 1: Adjust } \\
\text { Model 2: Adjust } \\
\text { of AF, type of A } \\
\text { bleeding, and sm }\end{array}$ & $\begin{array}{l}\text { for sociodemograp } \\
\text { for variables in mo } \\
\text { AF duration, medic } \\
\text { ing status }\end{array}$ & $\begin{array}{l}\text { variables: age, se } \\
11 \text {, clinical variabl } \\
\text { history of COPD, }\end{array}$ & $\begin{array}{l}\text { and race. } \\
\text { (BMI, symptoms } \\
\text { M2, HTN, Major }\end{array}$ \\
\hline
\end{tabular}

Table 3. Odds Ratios (95\% confidence intervals) for Cognitive Impairment vs. Not Cognitively

Impaired with Medical History of OSA

\begin{tabular}{|c|c|c|c|}
\hline $\begin{array}{l}\text { Medical } \\
\text { History of OSA }\end{array}$ & $\begin{array}{c}\text { Unadjusted } \\
\text { OR }(95 \% \text { CI })\end{array}$ & $\begin{array}{c}\text { Model } 1 \\
\text { OR }(95 \% \text { CI })\end{array}$ & $\begin{array}{c}\text { Model } 2 \\
\text { OR }(95 \% \text { CI })\end{array}$ \\
\hline $\mathrm{No}$ & Ref & Ref & Ref \\
\hline Yes & $0.79(0.59-1.05)$ & $0.99(0.72-1.36)$ & $0.80(0.56-1.13)$ \\
\hline \multicolumn{4}{|c|}{$\begin{array}{l}\text { Model 1: Adjusted for sociodemographic variables: age, sex, and race. } \\
\text { Model 2: Adjusted for variables in model 1, clinical variables (BMI; symptoms } \\
\text { of AF; type of AF; AF duration; medical history of COPD, DM2 HTN, Major } \\
\text { bleeding) and smoking status }\end{array}$} \\
\hline
\end{tabular}

Table 4. Odds Ratios (95\% confidence intervals) for reporting low AF-related quality of Life

“AFEQT < 80" (vs. high) with Medical History of OSA

\begin{tabular}{|c|c|c|c|}
\hline $\begin{array}{l}\text { Medical } \\
\text { History of OSA }\end{array}$ & $\begin{array}{c}\text { Unadjusted } \\
\text { OR }(95 \% \text { CI }) \\
\end{array}$ & $\begin{array}{c}\text { Model 1 } \\
\text { OR }(95 \% \text { CI })\end{array}$ & $\begin{array}{c}\text { Model } 2 \\
\text { OR }(95 \% \text { CI }) \\
\end{array}$ \\
\hline No & Ref & Ref & Ref \\
\hline Yes & $2.00(1.51-2.65)$ & $2.07(1.54-2.77)$ & $1.80(1.27-2.55)$ \\
\hline \multicolumn{4}{|c|}{$\begin{array}{l}\text { Model 1: Adjusted for sociodemographic variables: age, sex, and race. } \\
\text { Model 2: Adjusted for variables in model 1, clinical variables (BMI; symptoms } \\
\text { of AF; type of AF; AF duration; medical history of COPD, DM2, HTN, Major } \\
\text { bleeding) and smoking status }\end{array}$} \\
\hline
\end{tabular}

